Check for updates

Cite this: RSC Adv., 2018, 8, 29230

\title{
Vinyltriethoxysilane crosslinked poly(acrylic acid sodium) as a polymeric binder for high performance silicon anodes in lithium ion batteries $\uparrow$
}

\begin{abstract}
Xiangyu Zeng, Yongji Shi, Yu Zhang, Ruixian Tang and Liangming Wei (D) *
In order to effectively relieve the large volume changes of silicon anodes during the cycling process in lithium ion batteries (LIBs), we developed a vinyltriethoxysilane crosslinked poly(acrylic acid sodium) polymeric binder (PVTES-NaPAA) for the Si anodes. The PVTES-NaPAA binder was synthesized by using a free radical co-polymerization method with VTES and NaPAA as precursors. In this binder, NaPAA with carboxyl groups can provide strong adhesion between Si particles and the current collector. Furthermore, VTES can be hydrolyzed and condense with each other to form a three-dimensional crosslinked network; the special network makes it possible to improve the Si electrode stability, resulting in an excellent cycling performance (78.2\% capacity retention after 100 cycles) and high coulombic efficiency (99.9\% after 100 cycles).
\end{abstract}

Received 10th June 2018

Accepted 8th August 2018

DOI: $10.1039 / \mathrm{c} 8 \mathrm{ra04967j}$

rsc.li/rsc-advances

directly affect the cycle stability and capacity of the lithium-ion

\section{Introduction}

Nowadays, lithium-ion batteries are applied in various aspects in our life. ${ }^{1}$ As with the anode materials concerned, materials with high storage capacities have attracted tremendous interest in research. ${ }^{2-5}$ Among these materials, silicon (Si) materials process high theoretical capacity ( $4200 \mathrm{~mA} \mathrm{~h} \mathrm{~g}{ }^{-1}$ ), which is 11 times larger than that of the commercial graphite $\left(372 \mathrm{~mA} \mathrm{~h} \mathrm{~g}^{-1}\right) .^{6-8}$ Therefore, silicon has great potential to be the candidate of lithium-ion battery anode materials. However, the huge volume changes $(\sim 300 \%)$ of $\mathrm{Si}$ materials during the cycling process usually lead to electrical deactivation and fast capacity fading. ${ }^{9-12}$ To solve the problem, great efforts have been made including synthesising Si-based composites, preparing novel Si nanomaterials, designing Si crystal materials with special shapes, etc. ${ }^{13-16}$ As a part of the lithium battery material composition, the binder also has great influence on the cycle performance. Many researchers have prepared polymeric binders that can improve the cycle performance of electrode materials. ${ }^{17-20}$

Polymeric binders are usually used to bond the active material of the electrode with the conductive agent and the metal current collector. The properties of polymeric binders can

Key Laboratory for Thin Film and Microfabrication of the Ministry of Education, Department of Microelectronics and Nanoscience, School of Electronic Information and Electrical Engineering, Shanghai Jiao Tong University, 800 Dongchuan Road, Shanghai, 200240, China. E-mail: lmwei@sjtu.edu.cn; Fax: +86-21-34205665; Tel: +86-21-34205665

$\dagger$ Electronic supplementary information (ESI) available. See DOI: 10.1039/c8ra04967j batteries. With respect to Si anodes of the lithium-ion batteries, the polymeric binders should effectively accommodate the expansion of the silicon material during the charge-discharge process. ${ }^{21-23}$ Nowadays, poly(vinylidene fluoride) (PVDF) is one of the most widely used polymeric binders for Si anodes in the industry, but its poor adhesion with Si particles usually leads to bad cycle performance. ${ }^{24}$ In comparison of binders, a large number of studies shows that carboxymethyl cellulose $(\mathrm{CMC})^{25}$ and poly(acrylic acid) (PAA) ${ }^{20}$ are more effective binders to improve the capacity retention due to their carboxyl and hydroxyl groups. The ester bonding and hydrogen bonding can enhance the bond between the polymeric binders and the active materials, and further improve the cycling stability of the battery. ${ }^{25-27}$ However, the demerits of these binders include weak mechanical properties and electrode cracking during cycling. Considering the defects of those binders, functionalizing these common binders by grafting, crosslinking or blend can make it possible to improve the interaction between polymeric binders and silicon particles. For example, the crosslinked PAA functionalized with benzophenone group, crosslinked PAA and PVA, PAA-grafted CMC all significantly enhanced the electrochemical performance of Si-based LIBs. $^{28-32}$ However, the synthesize process of the polymeric binders is intricate and complex, a simple and effective polymeric binder system is required in LIBs.

Organofunctional silanes are important processing agents to improve the adhesive strength, mainly used as polymer composite additives. ${ }^{33}$ Vinyltriethoxysilane (VTES) is one of the most well-known organofunctional silanes, which possess 
excellent flexibility and adhesive properties. ${ }^{34-36}$ Herein, we develop a VTES crosslinked NaPAA polymer (PVTES-NaPAA) as the polymeric binder for silicon anodes in lithium ion batteries. The synthesis of the polymer is through free radical copolymerization method with VTES and acrylic acid monomer as the precursor. The PVTES-NaPAA polymeric binder can effectively improve the cycle stability of Si anodes and exhibit a high coulombic efficiency. Furthermore, the Si anodes with PVTES-NaPAA as the binder can also form a stable SEI film on the electrode surface during cycling.

\section{Experimental}

\subsection{Materials}

The Si nanoparticles (50-100 $\mathrm{nm}$ ) and the vinyltriethoxysilane (VTES) were obtained from Alfa Aesar. The lithium-foil and electrolyte were obtained from Shanghai Xiaoyuan Co. The initiator (ammonium peroxydisulfate) and other chemicals were purchased from Sinopharm Reagent Co.

\subsection{PVTES-NaPAA preparation}

Firstly, $0.2 \mathrm{~g}$ VTES and $4 \mathrm{~mL}$ acrylic acid monomer were dissolved in $80 \mathrm{~mL}$ distilled water. Secondly, the solution was moved into a $250 \mathrm{~mL}$ three-necked flask and the nitrogen was used to remove the oxygen in the solution for $6 \mathrm{~h}$. Thirdly, $0.1 \mathrm{~g}$ of the initiator was added into the solution. Then the solution was mechanical stirred for $4 \mathrm{~h}$ at $60{ }^{\circ} \mathrm{C}$ to prepare the PVTESNaPAA polymeric binder. The entire process keep nitrogen gas environment. Finally, the sodium hydroxide was used to neutralize the PVTES-NaPAA to $\mathrm{pH} 6$.

\subsection{Electrochemical experiments}

The electrochemical performance was tested by using CR2016 type half coin cells. The composition of the working electrodes includes Si nanoparticles, conductive carbon (Super P) and polymeric binders with $6: 2: 2$ weight ratio. The mass loading on the electrodes is about $0.5-1.3 \mathrm{mg} \mathrm{cm}^{-2}$. The lithium metal foil and the glass microfibre filter polymer were used as the counter electrode and the separator, respectively. The ethylene carbonate (EC) and dimethyl carbonate (DMC) (volume ratio $1: 1)$ with $10 \mathrm{wt} \%$ fluoroethylene carbonate (FEC) were mixed together as the Si-based anode electrolyte with $\operatorname{LiPF}_{6}(1 \mathrm{M})$ dissolved in it. The cyclic voltammetry (CV) curve was tested by CHI 760E electrochemical workstation (Chenhua Instruments Co., Shanghai, China). The testing voltage ranged from $0.01 \mathrm{~V}$ to 1.2 V. The cycling performance and rate capability were tested using the battery test system (LAND, Wuhan, China).

\subsection{Characterization methods}

The morphologies of the electrodes with binders were analyzed by using field-emission scanning electron microscopy (FE-SEM, Carl Zeiss Ultra 55). The crosslinked process was measured by using Fourier transform infrared (FTIR, Perkin-Elmer 70) spectroscopy with $\mathrm{KBr}$ pieces. The $180^{\circ}$ peel experiments and the tensile tests were carried out using the high-precision material mechanics test instrument (Hengyi Testing Machine Co., Shanghai, China).

\section{Results and discussion}

The PVTES-NaPAA binder was synthesized by using VTES and acrylic acid monomer as the precursor and ammonium persulfate as the initiator via a free radical co-polymerization process. The synthetic process of the PVTES-NaPAA polymeric binder is shown in Scheme 1. After heating, the initiator (ammonium peroxydisulfate) decomposed to generate anionic radical, which initiated co-polymerization of VTES and acrylic acid monomer. To confirm the copolymerization of the VTES and NaPAA, FT-IR spectra of PVTES-NaPAA, VTES and NaPAA were tested as shown in Fig. 1a. After polymerization, the absorption bands at $1160-1100 \mathrm{~cm}^{-1}$ (correspond to $\mathrm{Si}-\mathrm{O}$ from VTES) ${ }^{35}$ and 1571, $1452 \mathrm{~cm}^{-1}$ (correspond to $\mathrm{C}=\mathrm{O}$ in NaPAA) ${ }^{37}$ can be observed in PVTES-NaPAA. Furthermore, the absorption bands at $3064 \mathrm{~cm}^{-1}$ (correspond to $\mathrm{C}=\mathrm{C}-\mathrm{H}$ from VTES) disappeared. ${ }^{38}$ These results evidenced the successful formation of PVTES-NaPAA polymer. The ${ }^{1} \mathrm{H}$ NMR spectrum of PVTES-NaPAA

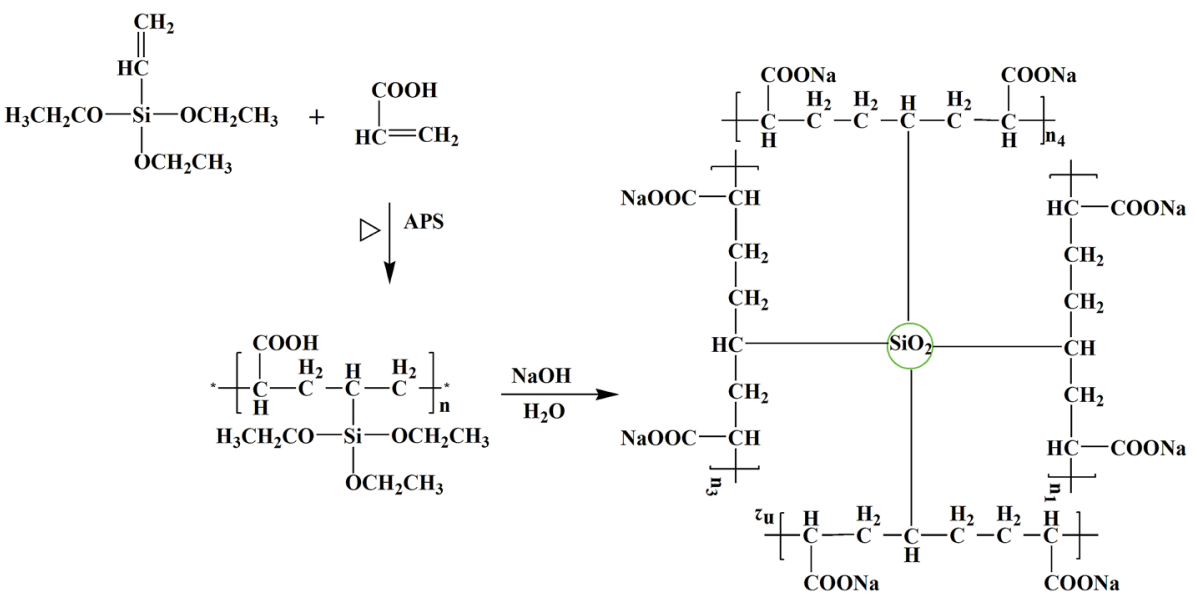

Scheme 1 The synthetic process of the PVTES-NaPAA binder. 

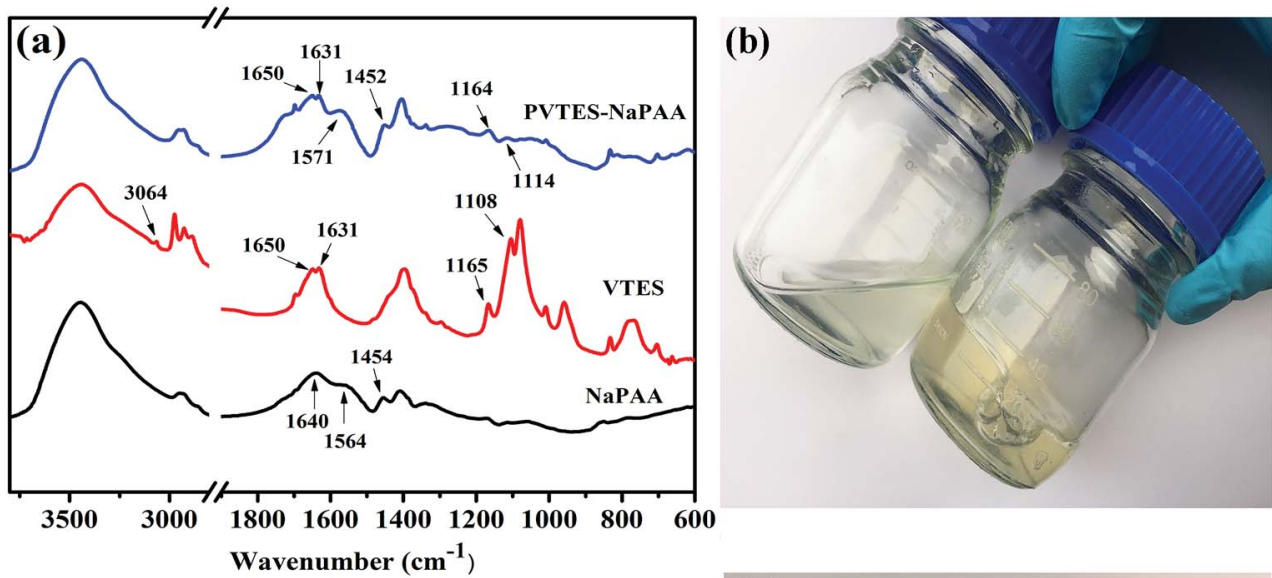

(d) $-\underset{b \quad \mathrm{CH}_{2} \mathrm{CH}_{3}}{-}$
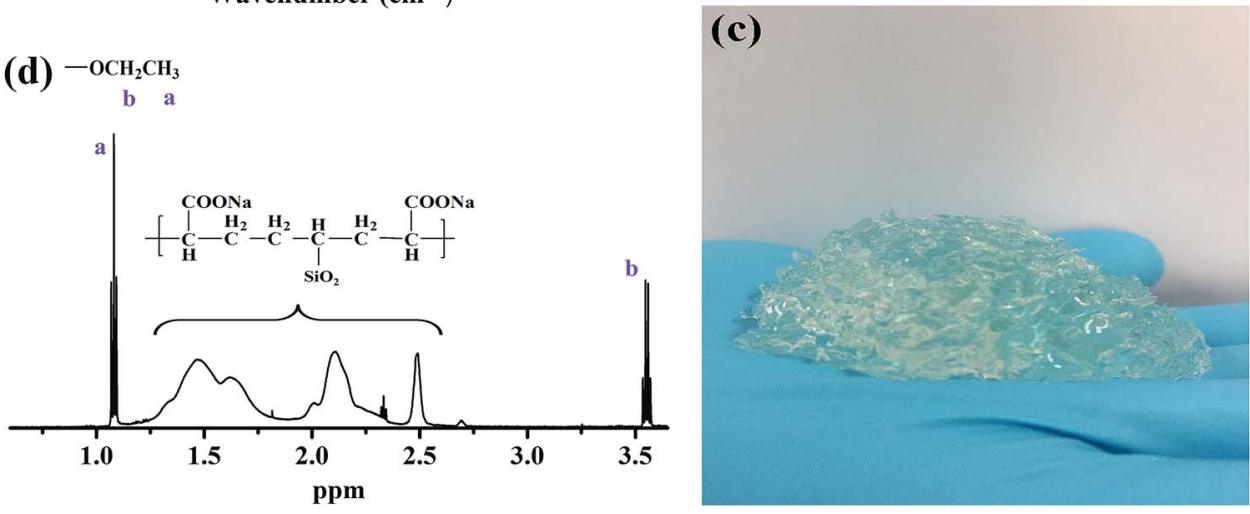

Fig. 1 (a) The FT-IR spectra of PVTES-NaPAA, VTES and NaPAA. (b) The PVTES-NaPAA polymer dissolved in water (left), polymeric binder PVTESNaPAA (right). (c) The robust gel after PVTES-NaPAA was dried and then immerged in water. (d) The ${ }^{1} \mathrm{H}$ NMR spectrum of PVTES-NaPAA.

(Fig. 1d) shows alkane (- $\left.\mathrm{CH}_{2}-\mathrm{CH}-\right)$ in PVTES and NaPAA (1.25$2.5 \mathrm{ppm})$, methyl group (1.08 ppm) and methylene group (3.55 ppm) in VTES. These results are consistent with the FT-IR spectra, which evidence successful copolymerization of VTES and NaPAA.

The PVTES-NaPAA polymer dissolved in water (Fig. 1b) and formed a clear solution, but a robust gel formed after PVTESNaPAA was dried and then immerged in water (Fig. 1c). Such gel formation was due to hydrolysis and then condensation of the ethyl silicate groups to form a crosslinked network for PVTES-NaPAA.

The electrochemical performance was evaluated with half coin cells. The working voltage of the cells ranged from $0.01 \mathrm{~V}$ to $1.2 \mathrm{~V}$ and the current density was $0.2 \mathrm{C}\left(840 \mathrm{~mA} \mathrm{~h} \mathrm{~g}^{-1}\right)$. Fig. $2 \mathrm{a}$ exhibits the galvanostatic voltage profile of $\mathrm{Si}$ anodes in the first cycle with PVTES-NaPAA as the binder. The discharge curve shows a slope during $1.0-0.30 \mathrm{~V}$, which corresponds to the formation of solid electrolyte interface (SEI) film. The discharge curve also displays a long platform during $0.30-0.01 \mathrm{~V}$, which means the lithium alloying process of crystalline silicon. ${ }^{39}$ Fig. 2b shows the cyclic voltammetry (CV) of the silicon electrode for the 1st, 3rd and 5th cycle. The two peaks at $0.33 \mathrm{~V}$ and $0.50 \mathrm{~V}$ can be attributed to the low-voltage delithiation and the high-voltage delithiation of amorphous Li-Si alloys. ${ }^{\mathbf{4 0 , 4 1}}$ Also, as shown in Fig. 2b, extra peaks can be observed at $0.21 \mathrm{~V}$ and $0.09 \mathrm{~V}$ after the first cycle, which indicate the crystal-to- amorphous transition. ${ }^{42}$ The weak peak at $0.09 \mathrm{~V}$ is invisible in the first few cycles, it can be ascribe to the overlap of strong cathodic peak in $0.01 \mathrm{~V}^{29}$

To exhibit the effect of different binders on the cycling stability, the PVTES-NaPAA was compared with common polymeric binders CMC, PVDF, NaPAA (denoted as Si $i_{\text {PVTES-NaPAA, }}$ $\mathrm{Si}_{\mathrm{CMC}}, \mathrm{Si}_{\text {PVDF}}, \mathrm{Si}_{\text {NaPAA }}$ ), as shown in Fig. 2c. The Si loading is about $0.54 \mathrm{mg} \mathrm{cm}^{-2}$ and the thickness of the electrode is about $15 \mu \mathrm{m}$, as shown in Fig. S1 (the ESI†). In the first cycle, the electrode with PVTES-NaPAA as the binder exhibited the high capacity of $2654 \mathrm{~mA} \mathrm{~h} \mathrm{~g}{ }^{-1}$. Furthermore, the capacity after 100 cycles can still remain $2077 \mathrm{~mA} \mathrm{~h} \mathrm{~g}{ }^{-1}$, about $78.2 \%$ capacity retention compared to the first cycle. In contrast, the electrodes with CMC and NaPAA binders only remain 57.9\%, 37.5\% after 100 cycles, respectively. The electrodes with PVDF binder even decayed to zero after 20 cycles. Obviously, the electrode using PVTES-NaPAA as the binder shows better cycle stability. Table $\mathrm{S} 1 \dagger$ also compares the cycling performance with different polymers as binders for silicon-based anodes for lithium ion batteries in the literature. The cycling performance in our work is good compared to the results in the table. Moreover, the coulombic efficiency (CE) of the electrode with PVTES-NaPAA binder was $89.0 \%$ at the first cycle, and it increased to $99.9 \%$ after 100 cycles. The high coulombic efficiency might suggest a relatively stable SEI film formation on the silicon electrode surface during cycling. Furthermore, even when the loading of 

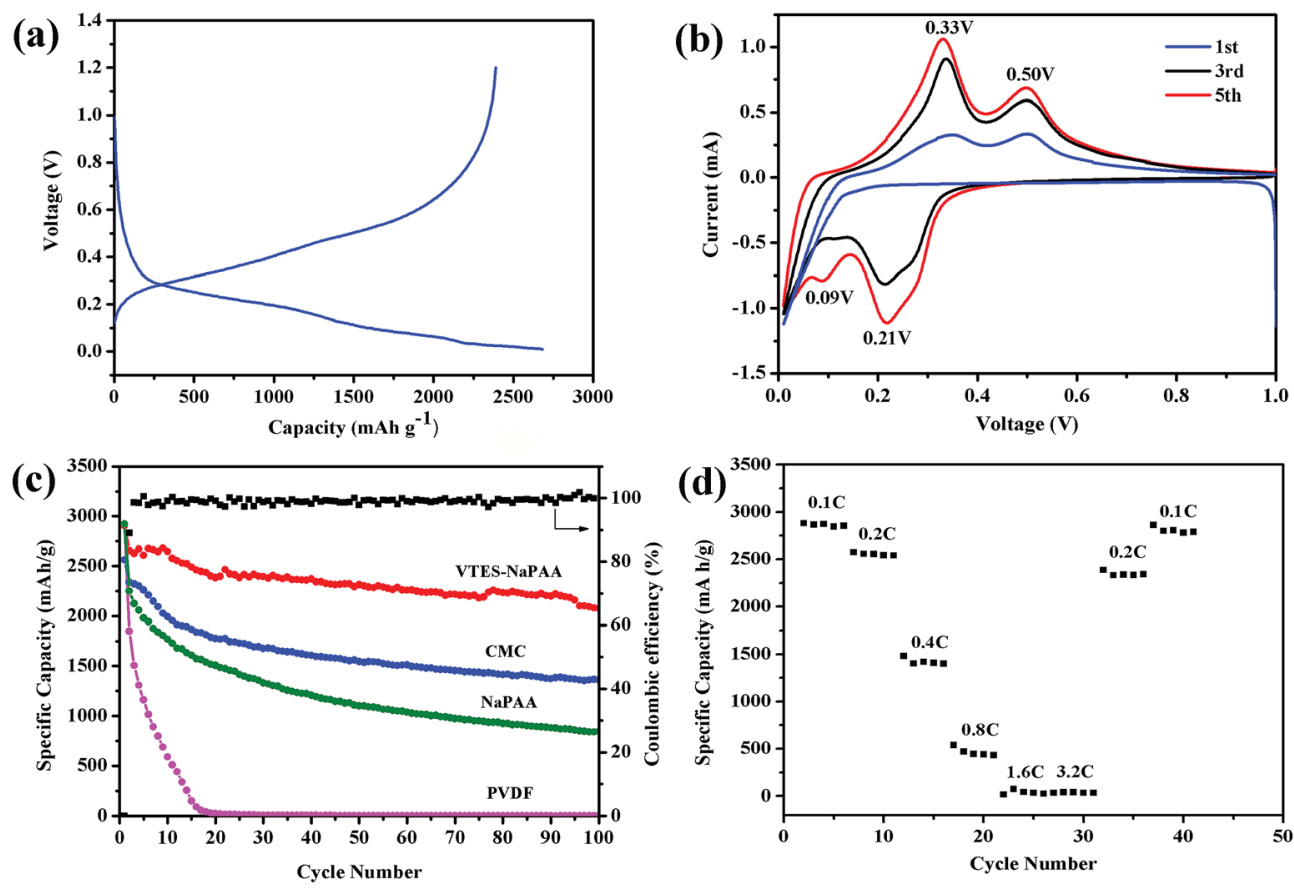

Fig. 2 (a) The voltage profile of the Si anode with PVTES-NaPAA binder during the first charge/discharge process. (b) The cyclic voltammetry (CV) of Si anodes with PVTES-NaPAA binder for the 1st, 3rd and 5th cycle. (c) The cycling performance of Si anodes with CMC, PVDF, NaPAA and PVTES-NaPAA binders. (d) The rate performance of the Si $\mathrm{PVTES}_{\text {NaPAA }}$ with different current density from 0.1C to 3.2C.

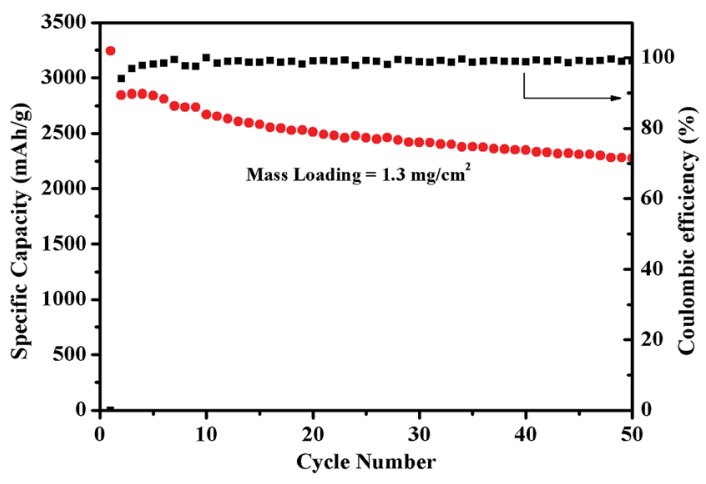

Fig. 3 The cycling performance of the Si anode with PVTES-NaPAA as the binder with the mass loading of $1.3 \mathrm{mg} \mathrm{cm}^{-2}$. electrode material increased to $1.3 \mathrm{mg} \mathrm{cm}^{-2}$, the capacity can also retain $80 \%$ after 50 cycles and the coulombic efficiency (CE) rose from $94 \%$ at the first cycle to $99 \%$, shown in Fig. 3 . Also, the cycling performance with the mass loading of $1.92 \mathrm{mg} \mathrm{cm}^{-2}$ is shown in Fig. S2. $\dagger$ The capacity after 50 cycles can still remain about $75.1 \%$ capacity compared to the first cycle.

Fig. $2 \mathrm{~d}$ shows the rate performance of the $\mathrm{Si}_{\text {PVTES-NaPAA }}$ with the current density increasing from $0.1 \mathrm{C}$ to $3.2 \mathrm{C}$. The reversible capacity of $\sim 500 \mathrm{~mA} \mathrm{~h} \mathrm{~g}{ }^{-1}$ at the current density of $0.8 \mathrm{C}$ can be observed in Fig. 2d. In addition, when the current density changes back to $0.2 \mathrm{C}$ and $0.1 \mathrm{C}$, discharge capacity basically rebounds to initial value, which confirms that the $\mathrm{Si}_{\text {PVTES-NaPAA }}$ has excellent reversibility.

Many studies have shown that binders play the role of bonding Si nanoparticles as well as the current collector and the
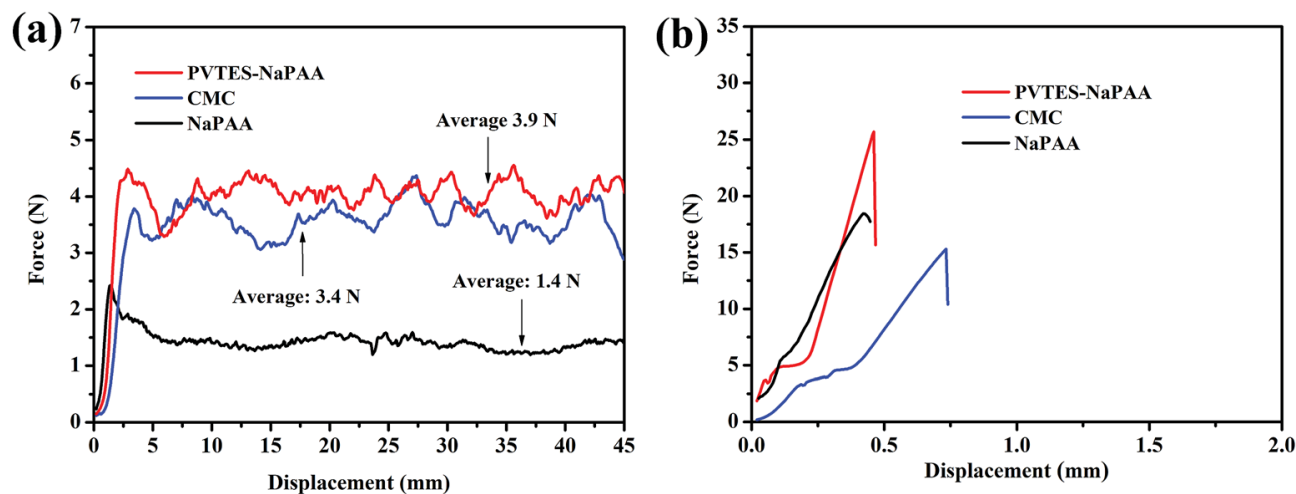

Fig. 4 (a) The $180^{\circ}$ peel experiment between the Si active material and the current collector with PVTES-NaPAA, CMC and NaPAA as binders. (b) The tensile tests of PVTES-NaPAA, CMC and NaPAA. 


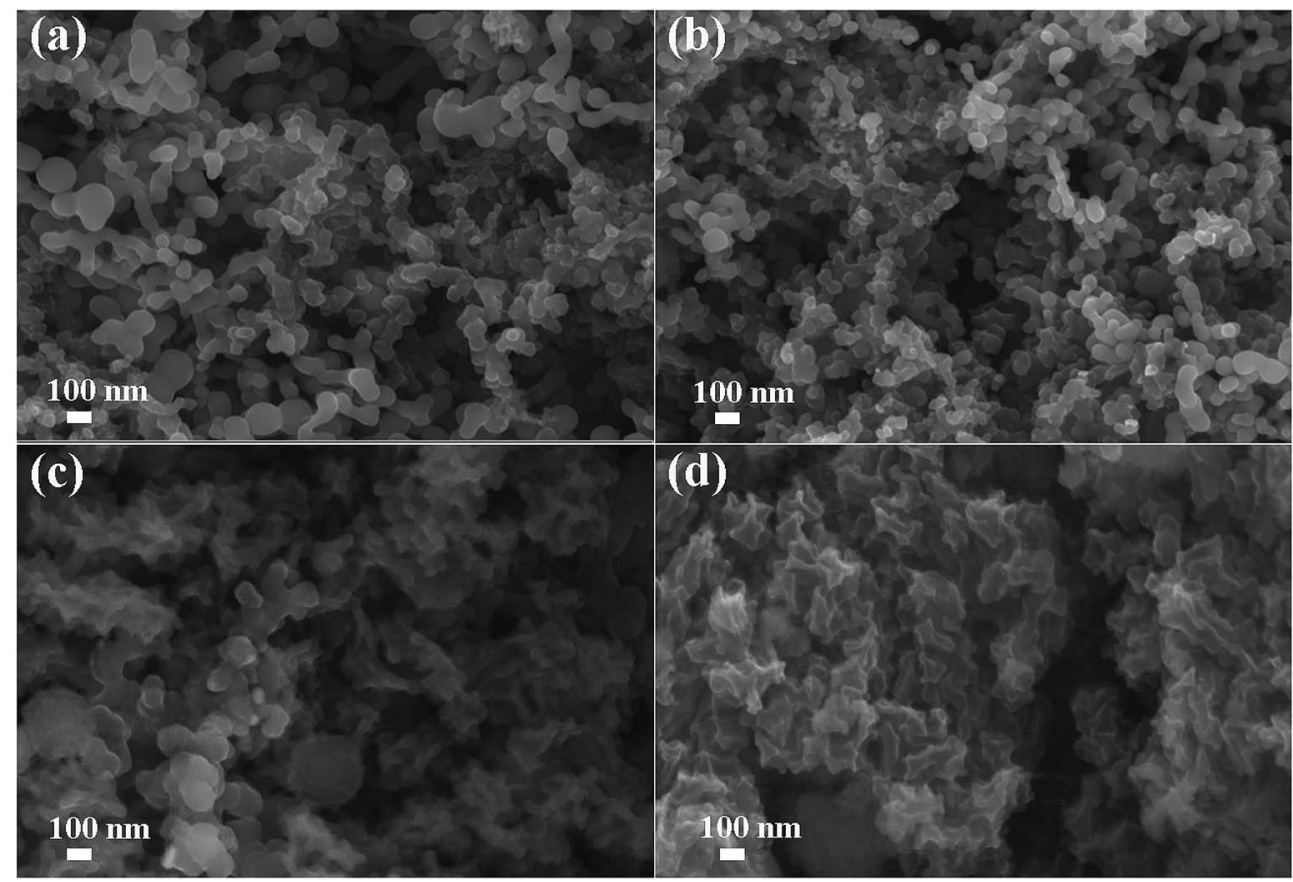

Fig. 5 SEM images of Si anodes with PVTES-NaPAA ( $a$ and $c$ ) and NaPAA ( $b$ and d) as binders before ( $a$ and b) and after (c and d) 100 cycles.

active material. ${ }^{43,44}$ The adhesion strength of binders is extremely important to maintain the stability of Si anodes electronic network. Herein, the $180^{\circ}$ peel experiment was used to evaluate the adhesion strength of different binders in Si anodes, as shown in Fig. 4a. The force-displacement curves in Fig. 4a show the adhesion between the $\mathrm{Si}$ active material and the current collector with PVTES-NaPAA, CMC and NaPAA as binders. The average peel force of the PVTES-NaPAA is $3.9 \mathrm{~N}$, which is much higher compared to CMC $(3.4 \mathrm{~N})$ and NaPAA $(1.4 \mathrm{~N})$. This higher peel force means that the PVTES-NaPAA might be more effective to make the Si electrode structure stable during cycling. ${ }^{43,44}$ The enhanced adhesion of the PVTES-NaPAA might be attributed to the multi-point contact of three-dimensional network structure, which compares to the linear structure of the CMC and NaPAA. ${ }^{28}$ Also, the adhesion test with the high loading of $0.9 \mathrm{mg} \mathrm{cm}^{-2}$ was carried out, as shown in Fig. S3. $\dagger$ From the figure, the average peel force is about $3.7 \mathrm{~N}$, which changes little compared to the low loading level of $3.9 \mathrm{~N}$.

Moreover, the mechanical property of binders is also a key factor for $\mathrm{Si}$ anodes. ${ }^{32}$ Binders which have higher Young's modulus can be more beneficial to maintain the electrode stability. ${ }^{43}$ The tensile test results in Fig. $4 \mathrm{~b}$ displays the PVTESNaPAA possesses the highest Young's modulus of 5.0 GPa, which is about 2 times than that of NaPAA (2.6 GPa) and CMC (2.0 GPa). This result suggests that the PVTES-NaPAA binder could effectively resist the deformation caused by volume expansion of Si anodes during cycling. ${ }^{43}$ The PVTES-NaPAA with excellent tensile strength could make the electrode be more stable during the cycling process of $\mathrm{Si}$ anodes. ${ }^{31}$

To deeply understand the effect of PVTES-NaPAA on the improvement of cycling performance, typical SEM images of Si electrodes with PVTES-NaPAA and NaPAA as polymeric binders were shown in Fig. 5. Fig. 5a and b show the uniformly porous structure of Si electrodes with PVTES-NaPAA and NaPAA as binders before cycling. However, obvious morphology changes were exhibited in these two samples after 100 cycles, shown in Fig. $5 \mathrm{c}$ and d. It can be observed that a thick SEI layer was on some areas of the electrode with NaPAA as the binder, as shown in Fig. $5 \mathrm{~d}$. This thick SEI film is considered to be the result of Si particles volume change and pulverization during cycling with new SEI film growing on them. ${ }^{45,46}$ In contrast, individual $\mathrm{Si}$

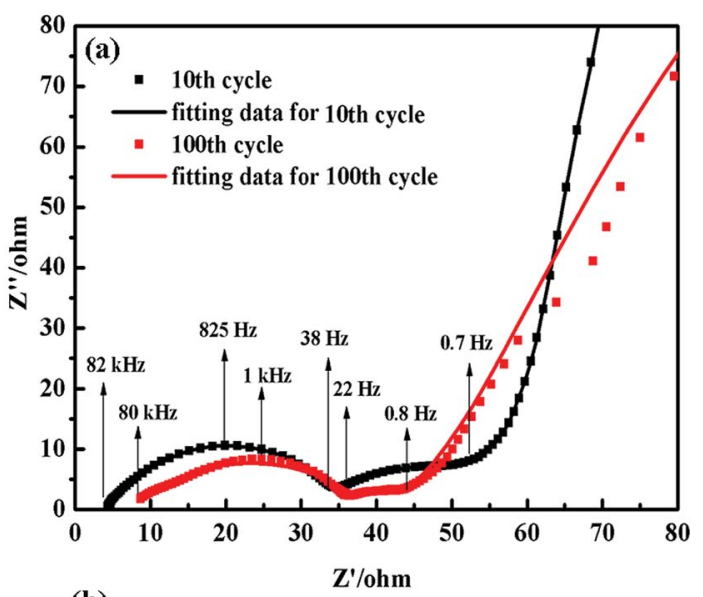

(b)

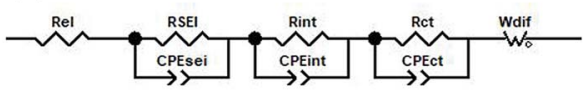

Fig. 6 (a) The Nyquist plots of the Si PVTES-NaPAA electrode at the $10^{\text {th }}$ cycle and the $100^{\text {th }}$ cycle. (b) The equivalent circuit for the Nyquist plots of the Si $i_{\text {PVTES-NaPAA }}$ electrode. 


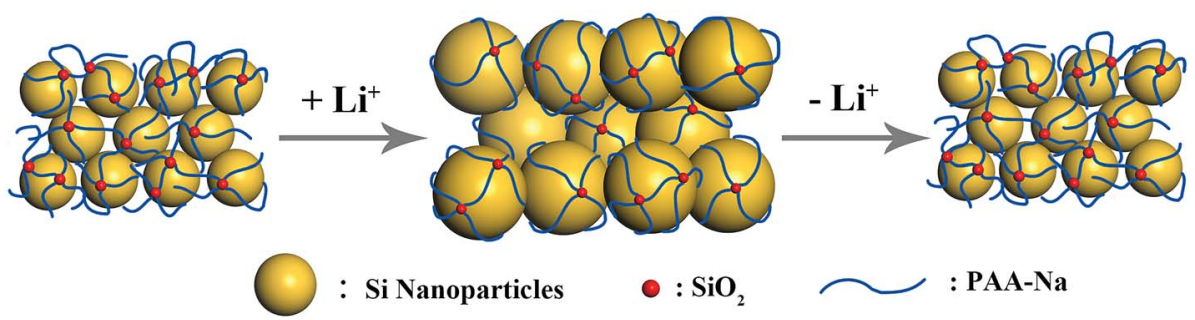

Scheme 2 The possible working mechanism of PVTES-NaPAA binder.

particle and porous structure was found for the electrode with PVTES-NaPAA as the binder after cycling, as shown in Fig. 5c. Thus, the uniform SEI film is believed to be formed in the PVTES-NaPAA sample. The formation of the thinner SEI film could be attributed to the PVTES-NaPAA crosslinked network which effectively accommodates the expansion of silicon materials during cycling. ${ }^{47}$

To further demonstrate the improved cycle stability, electrochemical impedance spectroscopy (EIS) measurements of the $\mathrm{Si}_{\text {PVTES-NaPAa }}$ electrode at the $10^{\text {th }}$ cycle and the $100^{\text {th }}$ cycle were performed in Fig. 6. As Fig. 6a shows, the Nyquist plots are composed by two approximate semicircles at high and middle frequency ranges as well as a Warburg tail at low frequency range. The general explanation of the Nyquist plots is that semicircles at high frequency range are ascribed to the SEI layer formation and the interphase electronic contact resistance between the anode material and the current collector $\left(R_{\text {SEI+int }}\right) .^{48}$ The semicircle at middle frequency range is due to the resistance of the charge transfer $\left(R_{\mathrm{ct}}\right)$. The Warburg tail corresponds to the $\mathrm{Li}^{+}$diffusion resistance $\left(W_{\mathrm{dif}}\right){ }^{48}$ According to the EIS spectra, the equivalent circuit for Nyquist plot of the $\mathrm{Si}_{\mathrm{PVTES}}$ NaPAA electrode (Fig. 6b) is provided. The equivalent circuit is constituted with four resistors, three constant phase elements in parallel and one Warburg diffusion element. It can be seen the fitting data of the $10^{\text {th }}$ and $100^{\text {th }}$ Nyquist plots (the solid lines in Fig. 6a) are consistent with the actual impedance data. According to the equivalent circuit, $R_{\mathrm{SEI}}, R_{\mathrm{int}}$ and $R_{\mathrm{ct}}$ were calculated. The SEI film resistance of the $\mathrm{Si}_{\mathrm{PVTES} \text {-NaPAA }}$ electrode is about $27 \Omega$ at the $10^{\text {th }}$ cycle, and about $24 \Omega$ at $100^{\text {th }}$ cycle. Such relatively stable $R_{\text {SEI }}$ suggests the stable SEI film formation for the $\mathrm{Si}_{\text {PVTES-NaPAA }}$ electrode during cycling, which expected a consistent result with the SEM results. The electrode also shows the decrease of the interphase electronic contact resistance from $10^{\text {th }}$ cycle $(21 \Omega)$ to $100^{\text {th }}$ cycle $(8 \Omega)$, suggesting the easily transformation of electrons from the $\mathrm{Si}$ electrode to the current collector during the cycling process. ${ }^{49}$

The better cycle performance of $\mathrm{Si}_{\text {PVTES-NaPAA }}$ could be interpreted by the special binding mechanism, which is different from CMC and PAA. The one-dimensional molecular structure of the CMC and PAA binders might only present one point contact with the Si particles. As a result, these linear structure binders could not bear the expansion and shrink of the Si particles during cycling. In comparison, the PVTESNaPAA binder with van der Waals interaction and hydrogen bonding could form a three-dimensional crosslinked network structure around the silicon particles, thus provide multi-point contacts with Si particles (Scheme 2). This forceful 3D polymer network with multi-point contact is beneficial to improve the electrode stability during the lithiation-delithiation cycling.

\section{Conclusions}

In summary, we have developed a polymeric binder PVTESNaPAA for high performance $\mathrm{Si}$ anodes by using free radical graft co-polymerization technique. The binder can effectively form a stable SEI film on the silicon anode surface, and accommodate volume changes of $\mathrm{Si}$ anodes, which resulting in good cycle performance $(78.2 \%$ capacity retention after 100 cycles) and high coulombic efficiency (99.9\% after 100 cycles). The PVTES-NaPAA binder has a great potential for Si anodes LIBs according to its excellent cycle stability, easy to synthesis and environmentally friendly.

\section{Conflicts of interest}

There are no conflicts to declare.

\section{Acknowledgements}

We acknowledge the U-M/SJTU Collaborative Research Program in Nanostructured Multi-functional Li-Batteries. We also acknowledge support from National Natural Science Foundation of China (No. 51272155). Special thanks to the Instrumental Analysis Center of Shanghai Jiao Tong University.

\section{References}

1 J. Xu, H. R. Thomas, R. W. Francis, K. R. Lum, J. Wang and B. Liang, J. Power Sources, 2008, 177, 512-527.

2 J. Xu, S. Dou, H. Liu and L. Dai, Nano Energy, 2013, 2, 439442.

3 S. Goriparti, E. Miele, F. De Angelis, E. Di Fabrizio, R. Proietti Zaccaria and C. Capiglia, J. Power Sources, 2014, 257, 421443.

4 C. Liu, F. Li, L. P. Ma and H. M. Cheng, Adv. Mater., 2010, 22, E28-E62.

5 G. W. X. Tang and Y. Song, Appl. Surf. Sci., 2018, 436, 398404.

6 M. N. Obrovac and L. Christensen, Electrochem. Solid-State Lett., 2004, 7, A93. 
7 B. Liang, Y. Liu and Y. Xu, J. Power Sources, 2014, 267, 469490.

8 M. Holzapfel, H. Buqa, L. J. Hardwick, M. Hahn, A. Würsig, W. Scheifele, P. Novák, R. Kötz, C. Veit and F.-M. Petrat, Electrochim. Acta, 2006, 52, 973-978.

9 U. Kasavajjula, C. Wang and A. J. Appleby, J. Power Sources, 2007, 163, 1003-1039.

$10 \mathrm{H}$. Wu and Y. Cui, Nano Today, 2012, 7, 414-429.

11 J. Li and J. R. Dahn, J. Electrochem. Soc., 2007, 154, A156.

12 Q. Tang, Z. Shan, L. Wang and X. Qin, Electrochim. Acta, 2012, 79, 148-153.

13 H. K. Liu, Z. P. Guo, J. Z. Wang and K. Konstantinov, J. Mater. Chem., 2010, 20, 10055.

14 M. K. Datta and P. N. Kumta, J. Power Sources, 2009, 194, 1043-1052.

15 K. Hanai, Y. Liu, N. Imanishi, A. Hirano, M. Matsumura, T. Ichikawa and Y. Takeda, J. Power Sources, 2005, 146, 156-160.

16 S. H. Yook, C. H. Park and D. W. Kim, RSC Adv., 2016, 6, 83126-83134.

17 B. Koo, H. Kim, Y. Cho, K. T. Lee, N. S. Choi and J. Cho, Angew. Chem., Int. Ed. Engl., 2012, 51, 8762-8767.

18 M. H. Ryou, J. Kim, I. Lee, S. Kim, Y. K. Jeong, S. Hong, J. H. Ryu, T. S. Kim, J. K. Park, H. Lee and J. W. Choi, Adv. Mater., 2013, 25, 1571-1576.

19 Z. J. Han, N. Yabuuchi, S. Hashimoto, T. Sasaki and S. Komaba, ECS Electrochem. Lett., 2012, 2, A17-A20.

20 A. Magasinski, B. Zdyrko, I. Kovalenko, B. Hertzberg, R. Burtovyy, C. F. Huebner, T. F. Fuller, I. Luzinov and G. Yushin, ACS Appl. Mater. Interfaces, 2010, 2, 3004-3010.

$21 \mathrm{M}$. Wu, X. Xiao, N. Vukmirovic, S. Xun, P. K. Das, X. Song, P. Olalde-Velasco, D. Wang, A. Z. Weber, L. W. Wang, V. S. Battaglia, W. Yang and G. Liu, J. Am. Chem. Soc., 2013, 135, 12048-12056.

22 Y.-S. Park, E.-S. Oh and S.-M. Lee, J. Power Sources, 2014, 248, 1191-1196.

23 H. Wu, G. Zheng, N. Liu, T. J. Carney, Y. Yang and Y. Cui, Nano Lett., 2012, 12, 904-909.

24 L. Chen, X. Xie, J. Xie, K. Wang and J. Yang, J. Appl. Electrochem., 2006, 36, 1099-1104.

25 J. S. Bridel, T. Azaïs, M. Morcrette, J. M. Tarascon and D. Larcher, Chem. Mater., 2010, 22, 1229-1241.

26 S. L. Chou, Y. Pan, J. Z. Wang, H. K. Liu and S. X. Dou, Phys. Chem. Chem. Phys., 2014, 16, 20347-20359.

27 J. Li, R. B. Lewis and J. R. Dahn, Electrochem. Solid-State Lett., 2007, 10, A17.

28 L. Wei, C. Chen, Z. Hou and H. Wei, Sci. Rep., 2016, 6, 19583.

29 L. Shen, L. Shen, Z. Wang and L. Chen, ChemSusChem, 2014, 7, 1951-1956.
30 J. Song, M. Zhou, R. Yi, T. Xu, M. L. Gordin, D. Tang, Z. Yu, M. Regula and D. Wang, Adv. Funct. Mater., 2014, 24, 59045910.

31 L. Wei and Z. Hou, J. Mater. Chem. A, 2017, 5, 22156-22162. 32 Y. Park, S. Lee, S.-H. Kim, B. Y. Jang, J. S. Kim, S. M. Oh, J.-Y. Kim, N.-S. Choi, K. T. Lee and B.-S. Kim, RSC Adv., 2013, 3, 12625.

33 J. Wang, C. Xu, H. Hu, L. Wan, R. Chen, H. Zheng, F. Liu, M. Zhang, X. Shang and X. Wang, J. Nanopart. Res., 2010, 13, 869-878.

34 S.-M. Yuen, C.-C. M. Ma, C.-L. Chiang, C.-C. Teng and Y.-H. Yu, J. Polym. Sci., Part A: Polym. Chem., 2008, 46, 803816.

35 C. Jiao, Z. Wang, Z. Gui and Y. Hu, Eur. Polym. J., 2005, 41, 1204-1211.

36 M. T. Jeena, T. Bok, S. H. Kim, S. Park, J. Y. Kim, S. Park and J. H. Ryu, Nanoscale, 2016, 8, 9245-9253.

37 Y. Liu, W. Wang and A. Wang, Desalination, 2010, 259, 258264.

38 E. A. W. Anya Kuznetsova and J. T. Yates Jr, Langmuir, 1997, 13, 5322-5328.

39 H. Wu, G. Chan, J. W. Choi, I. Ryu, Y. Yao, M. T. McDowell, S. W. Lee, A. Jackson, Y. Yang, L. Hu and Y. Cui, Nat. Nanotechnol., 2012, 7, 310-315.

40 M. Thakur, S. L. Sinsabaugh, M. J. Isaacson, M. S. Wong and S. L. Biswal, Sci. Rep., 2012, 2, 795.

41 X. Chen, X. Li, F. Ding, W. Xu, J. Xiao, Y. Cao, P. Meduri, J. Liu, G. L. Graff and J. G. Zhang, Nano Lett., 2012, 12, 4124-4130.

42 C. K. Chan, R. Ruffo, S. S. Hong, R. A. Huggins and Y. Cui, J. Power Sources, 2009, 189, 34-39.

43 S. J. C. T. Yim, Y. N. Jo, T. H. Kim, K. J. Kim, G. Jeong and Y. J. Kim, Electrochim. Acta, 2014, 136, 112-120.

44 G. Y. Y. Xu, Y. Ma, P. Zuo and X. Cheng, J. Power Sources, 2010, 195, 2069-2073.

45 C. K. Chan, H. Peng, G. Liu, K. McIlwrath, X. F. Zhang, R. A. Huggins and Y. Cui, Nat. Nanotechnol., 2007, 3, 31-35.

46 J. Song, T. Xu, M. L. Gordin, P. Zhu, D. Lv, Y.-B. Jiang, Y. Chen, Y. Duan and D. Wang, Adv. Funct. Mater., 2014, 24, 1243-1250.

47 S. H. Zhen Liu, C. Xu, Y. Luo, N. Peng, C. Qin, M. Zhou, W. Wang, L. Chen and S. Okada, RSC Adv., 2016, 6, 6837168378.

48 J. Guo, A. Sun, X. Chen, C. Wang and A. Manivannan, Electrochim. Acta, 2011, 56, 3981-3987.

49 Y. C. S. Y. Lee, K. S. Hong, J. K. Lee, J. Y. Kim, J. S. Bae and E. D. Jeong, Appl. Surf. Sci., 2018, 447, 442-451. 